\title{
The Study on the Damage of the Rear-Axle Shaft in a KIA Truck
}

\author{
Marek Wozniak', Gustavo Ozuna ${ }^{2}$, Krzysztof Siczek $^{1 *}$ \\ 1 Department of Vehicles and Fundamentals of Machine Design, Lodz University of Technology, Lodz, Poland \\ 2 Department of Industrial and Systems Engineering University of Sonora, Hermosillo, Mexico \\ * Corresponding author's e-mail: ks670907@p.lodz.pl
}

\begin{abstract}
Nowadays, trucks are widely used in the freight transport. Every accident involving a truck as well as any longer disruption of its traffic flow causes great losses. The considered disturbance in traffic flow occurred for a truck with dual tires on its rear axle resulted from the damage to the power transmission system from the engine to the drive wheels of the track. Investigating the cause of one such damage, in the form of rupture of the rear driveshaft, was the purpose of this article. The parameters of the analyzed truck, its wheels, its engine characteristics, the scheme of its cornering, the model of its rear-axle shaft, and the model of loading the bearing set of its rear dual wheel were included in the paper. Additionally, the probable cause of the truck rear axle shaft breakage was established.
\end{abstract}

Keywords: truck, rear axle-shaft, failure

\section{INTRODUCTION}

Nowadays, many kinds of trucks are utilized for the purposes of long-haul or regional delivery. According to [15], over 6 million trucks with an average age of 12 years are used throughout the EU.

According to the actual European classification system, trucks are defined as "motor vehicles with at least four wheels, used for the carriage of goods". Their mass is greater than 3.5 tonnes. There are two categories of trucks: N2 for the trucks with mass over 3.5 tonnes and N3 for the trucks with mass greater than 16 tonnes. Trucks can have differ in terms of the number of axles, the size of the engine, fuel tank or cab, and the height of the chassis.

Almost $77 \%$ of all freight transported overland is carried by trucks. Due to the high flexibility, they are often used in transport as $85 \%$ of road freight tonnage is carried over distances shorter than $150 \mathrm{~km}$. They also greatly affect the proper function of the logistics chain containing such components as inland waterways, shipping, air and rail transport. Some transport modes depend on trucks carrying freight to and from depots, rail terminals, airfields and ports.
Every accident involving a truck as well as any longer disruption of its traffic flow causes great losses for both the person ordering the transport and the owner of the transport fleet.

The Federal Motor Carrier Safety Administration (FMCSA) [3] reported that almost $9 \%$ of all large truck crashes were caused by rollovers characterized as an events with "one or more vehicle quarter turns about the longitudinal axis".

Garcia et al. [4] investigated the behavior of a five-axle tractor-trailer unit carrying different weight loads along roadway curves with different radii under normal operating conditions. Even when travelling with the speed in the range of the posted limit, the lateral accelerations of the trailer exceeded the expected lateral accelerations under all studied load configurations.

Green [5] found that rollovers occurred with particular frequency on freeway ramps and inclines and recommended the use of sensor activated warning signs detecting unsafe approaches.

Khattak and Schneider [12] found that rollovers caused $30 \%$ of crashes.

Dilich and Goebelecker [2] stated that many rollovers resulted from the driver errors, such as excessive speed in curves, misjudging sharpness, 
drifting off-road, counter-steering abruptly, not adjusting to the trailers high center of gravity, physical impairing (e.g. fatigue, drowsiness) or an emotional one (recklessness, angriness). The problems related to the vehicle concerned: topheavy and badly distributed or unsecured loads, poorly maintained brakes or suspension and under-inflated tires, needed the driver's check.

According to [13], almost 120 truck rollovers were caused excessive speed which was not adjusted to the curves in the road, (mostly on-and off-ramps), the carried loads, condition of the brakes, road surface, and intersection conditions. A second major group of crashes resulted from inattention, dozing or falling asleep, and distraction, in some situations indirectly causing a rollover. The third large group of crashes was caused by over-steering to the point of rolling over, not steering enough to stay in lane, and overcorrecting to the point of having to counter-steer to remain on the road. Sometimes, drivers failed to consider the weight of carried loads, height or security, or when loading was realized before they were assigned.

Guimaraes et al. [6] reported a premature failure of a half-shaft of the transmission system of a racing car. Such a failure resulted from the insufficient loading capacity and fatigue resistance of the alloy steel bar used for the half-shaft. The occurred fracture process was a total result of torsional fatigue crack propagation and overload ductile fracture through the spline section of the half-shaft.

Das et al. [1] analyzed the failure of a forklift's axle shaft transmitting torque from discrepancy to the wheel via the planetary gear. The shaft made of $42 \mathrm{CrMo} 4$ steel grade was improperly heat-treated. This caused a brittle case, where the crack was initiated due to differences in the microstructure. Such a microstructure was martensitic within the case and a mixture of the non-homogeneous structure of pearlite and ferrite within the core. The inclusions along the hot working direction i.e. in the longitudinal axis, were also conducive to the component failure.

According to [14] dual tires are mounted on the non-steering axles of heavy-duty commercial trucks. This allows increasing their load capacity and improving drivability of a vehicle with a flat rear tire. The installation of two tires on both ends of a single axle allows twice greater weight carried by the axle and also makes it possible that three properly inflated tires temporarily carry the weight originally allocated to the four tires when the pressure in a rear tire reaches insufficient values or such a tire goes flat.

Dual tires can also be found on the rear axles of recreational vehicle motorhomes (RVs) and heavy duty, 3/4-ton and 1-ton pickup trucks. The use of the same size tires and wheels singly on the steering axle and doubled on the drive axle allows increasing the load capacity of the vehicle. Additionally, all tires can be rotated periodically and a single spare tire and wheel can be used in the vehicle.

The considered disturbance in traffic flow for a truck with dual tires on its rear axle was caused by damage to the power transmission system from the engine to the drive wheels of the track. Investigating the cause of one such damage, in the form of rupture of the rear driveshaft, was the purpose of this article.

\section{Elements of the drive power transmission system}

The operation of a truck needs the transfer of the engine power and torque to the wheels via the transmission system. Such a system possesses the build characteristics according to the truck rear-wheel drive style. The rear-wheel drive spreads the road loads of the vehicle across all four tires. In a rear-wheel drive truck, the rear wheels are driven while the front wheels allow for steering.

Figure 1 shows the components of a rearwheel drive transmission system [7]. Such components are namely: clutch, gearbox, propeller shaft, universal joints, differential, drive shafts and tires. The axle (final drive) includes differential and drive shafts which are explained in the next section. Many different design and construction properties of each element strictly depend on the vehicle manufacturer.

\section{METHODS AND MATERIALS}

\section{The analyzed truck}

The analyzed truck was a KIA K2700 [9]. The specifications of such a vehicle are presented in Table 1. The scheme of such a vehicle was shown in Figure 2. The analyzed vehicle had a manual 5 -speed transmission with a clutch locking system. Its gear ratios were presented in Table 2 [11]. 


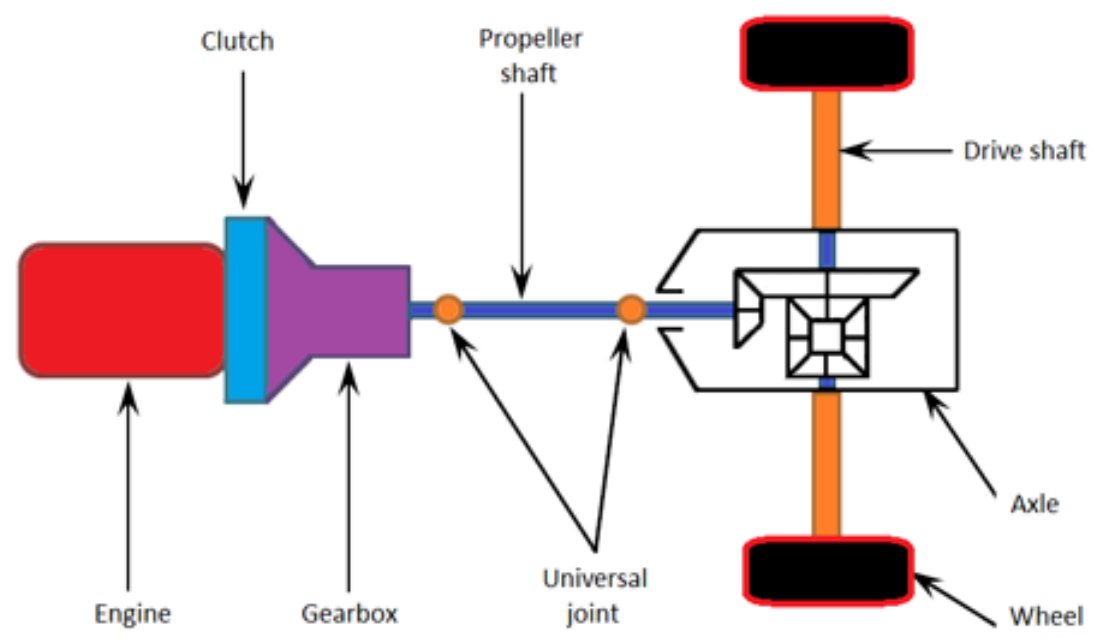

Fig. 1. Components of a rear-wheel drive transmission system.

\section{The wheels of the analyzed truck}

The rear wheels are presented in Figure 2. Using the rear tire specifications, namely $155 \mathrm{R} 12 \mathrm{C}$ (width equal to $155 \mathrm{~mm}$, rim diameter equal to 12 ", $\mathrm{R}$ - radial construction, aspect ratio equal to 0.8 ) the radius of the rear wheel $R_{t}[\mathrm{~m}]$ was estimated from the equation.

$$
R_{t}=\frac{12 \cdot 2,54+2 \cdot 0.8 \cdot 15.5}{2 \cdot 100}=0.2764[\mathrm{~m}]
$$

Similarly, the front tire specifications, namely 195R14C, allowed estimating the radius of the front wheel $R_{t}[\mathrm{~m}]$ from equation.

Table 1. Specifications of the analyzed vehicle

\begin{tabular}{|l|c|c|}
\hline \multirow{4}{*}{ Dimensions (mm) } & Model & K2700 \\
\cline { 2 - 3 } & Rear deck & Long / Low \\
\cline { 2 - 3 } & Cabin type & Standard \\
\cline { 2 - 3 } & Seat capacity & 3 \\
\hline Overall length & $L_{\text {oa }}$ & 4.825 \\
\hline Overall width & $B_{\text {oa }}$ & 1.740 \\
\hline Overall height & $H_{\text {oa }}$ & 1.975 \\
\hline Wheelbase & $L$ & 2.415 \\
\hline Front overhang & $L_{\text {ohf }}$ & 1.205 \\
\hline Rear overhang & $L_{\text {ohr }}$ & 1.205 \\
\hline Front wheeltread & $B_{\mathrm{f}}$ & 1.490 \\
\hline Rear wheeltread & $B_{\mathrm{r}}$ & 1.340 \\
\hline Rear deck length & $L_{\mathrm{rd}}$ & 2.810 \\
\hline Rear deck width & $B_{\mathrm{rd}}$ & 1.630 \\
\hline Rear deck height & $H_{\mathrm{rd}}$ & 355 \\
\hline Rear deck deck height & $H_{\mathrm{rdrd}}$ & 754 \\
\hline Ground clearance & $H_{\mathrm{gc}}$ & 145 \\
\hline Fuel tank capacity (litres) & $V_{\mathrm{ftc}}$ & 60 \\
\hline
\end{tabular}

$R_{t}=\frac{14 \cdot 2,54+2 \cdot 0.8 \cdot 19,5}{2 \cdot 100}=0.3338[\mathrm{~m}]$

\section{The engine characteristics of the analyzed truck}

According to [10], the analyzed vehicle was driven by a 2.7 (J2) diesel engine. The displacement of such an engine was equal to $2665 \mathrm{cc}$. Its maximum power of $66 \mathrm{~kW}$ was reached at $4000 \mathrm{rpm}$. Its maximum torque of $165 \mathrm{Nm}$ was reached at $2400 \mathrm{rpm}$.

The engine characteristics obtained under $25 \%, 50 \%, 75 \%$ and $100 \%$ loading were presented in Figures 3 and 4.

\section{Scheme of cornering}

The analyzed vehicle was overloaded, such that its total weight was equal to $3700 \mathrm{~kg}$, although its Gross Vehicle Mass was equal to $2850 \mathrm{~kg}$ [8]. The height of the gravity centre $h_{c}$ was equal to $0.8 \mathrm{~m}$. The distance of the gravity center from the front vehicle axis $\mathrm{a}_{\mathrm{c}}$ was equal to $1.72 \mathrm{~m}$ and from the rear wheel axis $b_{c}$ was equal to $0.69 \mathrm{~m}$. During cornering, the vehicle rode with a constant speed $v$ of $30 \mathrm{kph}$ and the radius of corner $R$ was equal to $10 \mathrm{~m}$. This resulted in the conditions.

$$
\frac{d v}{d t}=0
$$

The scheme of the forces and torques acting on the vehicle during cornering was presented in Figure 6a. The simplified sets of such forces and torques was presented in Figures $6 \mathrm{~b}$ and $6 \mathrm{c}$. 


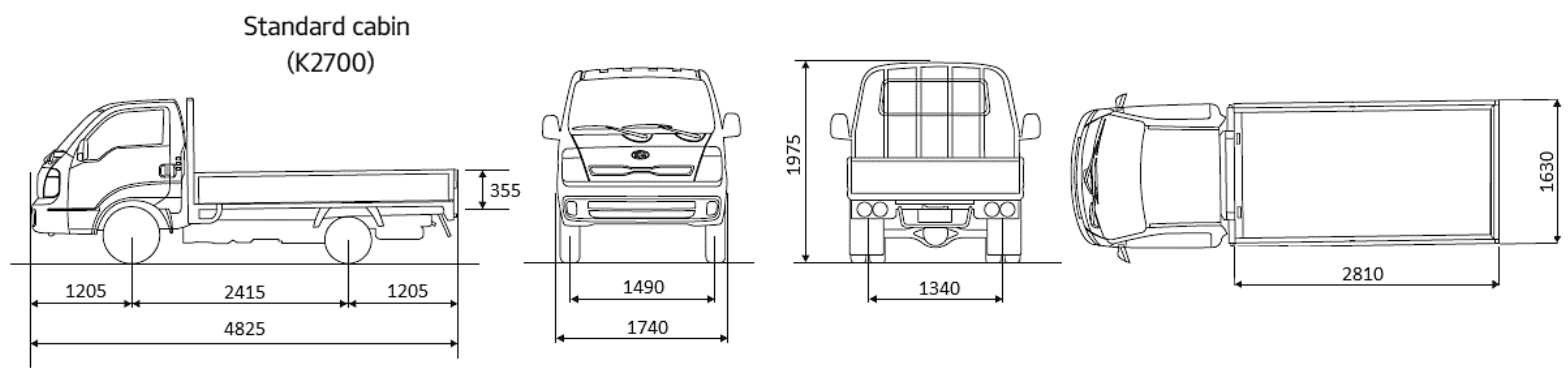

Fig. 2. The scheme of analyzed KIA K2700 truck

It was assumed that in case of driving, the torque transferred to the rear wheels the force $\mathrm{P}_{\mathrm{y}}$ is very small in comparison to the forces $\mathrm{F}_{1}$ and $\mathrm{F}_{2}$.

The forces $F_{1}$ and $F_{2}$ are the sums of the component forces acting on front and rear parts of vehicle wheel, respectively.

$$
\begin{aligned}
& F_{1} \approx F_{1}^{\prime}+F_{1}^{\prime \prime} \\
& F_{2}=F_{2}^{\prime}+F_{2}^{\prime \prime}
\end{aligned}
$$

The force $\mathrm{N}$ is estimated from the following equation

$$
N=\frac{m \cdot v^{2}}{R}
$$

During the cornering, the total force driving the vehicle $P_{n}[N]$ was estimated from equation.

Table 2. Gear ratios for KIA K2700

\begin{tabular}{|c|c|c|}
\hline \multicolumn{2}{|c|}{ Gear } & Gear ratio \\
\hline 1st / 2nd & $i_{I} / i_{I I}$ & $4.117 / 2.272$ \\
\hline 3rd / 4th & $i_{I I I} / i_{I V}$ & $1.425 / 1.000$ \\
\hline 5th / rev & $i_{V} / i_{r}$ & $0.871 / 3.958$ \\
\hline Final & $i_{f}$ & 3.727 \\
\hline
\end{tabular}

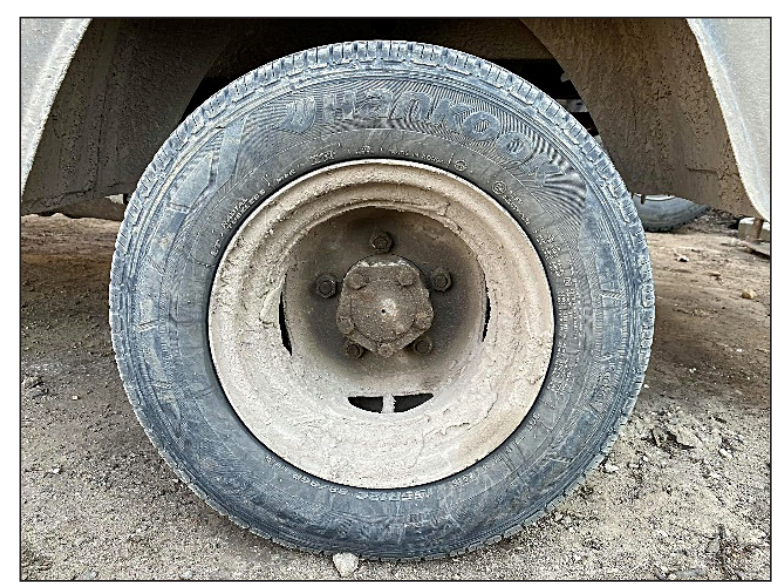

Fig. 3. Rear wheel of the KIA K2700 truck

$$
P_{n}=f \cdot G \cdot \cos \left(\tan ^{-1}\left(\frac{L}{R}\right)\right)+0.5 \cdot \rho \cdot C_{x} \cdot A \cdot v^{2}
$$

where: $f=0.05-$ rolling resistance,

$\mathrm{G}=36297 \mathrm{~N}-$ vehicle weight,

$\rho=1.25 \mathrm{~kg} \times \mathrm{m}^{-3}-$ air density,

$\mathrm{C}_{\mathrm{x}}=0.8-$ drag coefficient,

$A=B_{o a} \cdot H_{o a}=3.44 \mathrm{~m}^{2}$-reference front area of vehicle.

Total gear ratio for the vehicle was obtained from equation:

$$
i_{t}=i_{I I} \cdot i_{f}=8.47
$$

It was assumed that the efficiency $h$ of driving set was equal to 0.9 .

The torque of the engine $M_{e}[\mathrm{Nm}]$ was calculated from equation.

$$
M_{e}=\frac{P_{n} \cdot R_{t}}{i_{t} \cdot \eta}
$$

The engine speed $\eta_{e}[\mathrm{rpm}]$ was calculated from equation

$$
n_{e}=i_{t} \cdot \frac{v}{R_{t}} \cdot \frac{30}{\pi}
$$

The reaction acting on the outer rear vehicle during cornering was estimated from equation.

$$
\begin{gathered}
R_{r o}=0.5 \cdot\left(G \cdot \frac{a_{c}}{L} \cdot \cos \left(\tan ^{-1}\left(\frac{L}{R}\right)\right)+\frac{M_{e} \cdot i_{t} \cdot \eta}{R_{t}} \cdot \frac{h_{c}}{L}\right)+ \\
+m \cdot \frac{v^{2}}{R} \cdot \frac{h_{c}}{B_{r}} \cdot \frac{a_{c}}{L}
\end{gathered}
$$

\section{Model of rear-axle shaft}

The model of the rear-axle shaft of the KIA K2700 truck was elaborated using the Finite Element Method. The geometry of the shaft was shown in Figure 7a. The rear-axle shaft was made of C55 tempered steel. Its yield stress $\mathrm{R}_{\mathrm{e}}$ was equal to $550 \mathrm{MPa}$. It was assumed that its allowable value of fatigue strength was equal to $k_{\text {fatigue }}=0.42 \cdot R_{e}$, i.e. to $230 \mathrm{MPa}$. The grid 


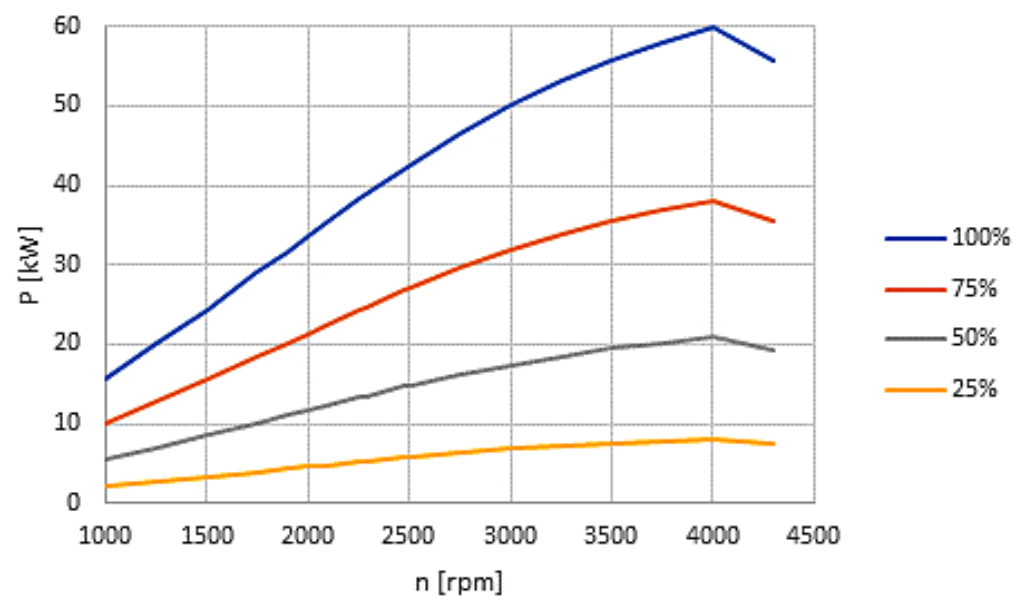

Fig. 4. The engine power $P$ vs engine speed $n$ for $25 \%, 50 \%, 75 \%$ and $100 \%$ loading of the KIA $2.7(\mathrm{~J} 2)$ diesel engine

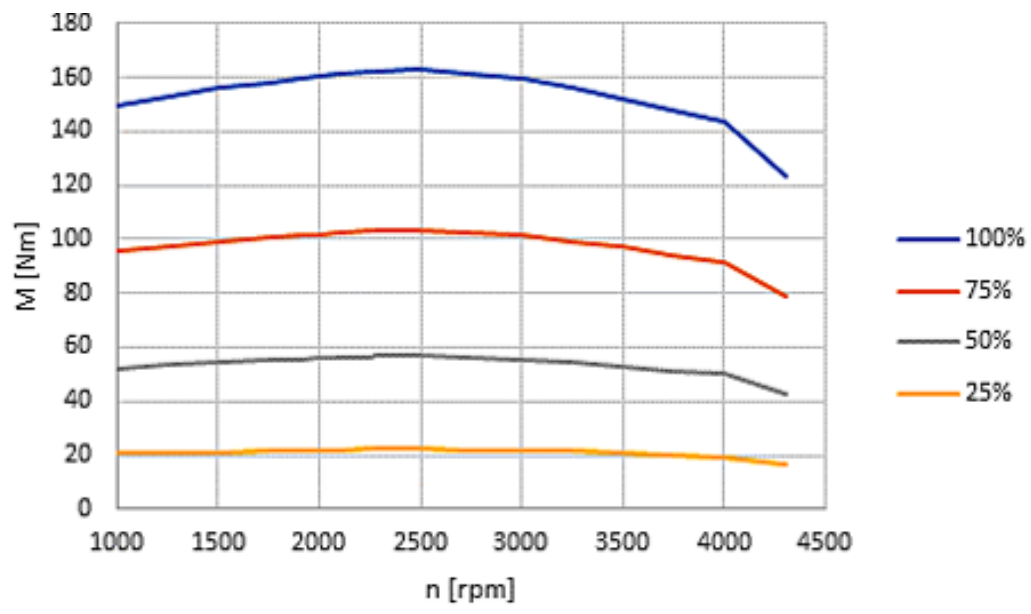

Fig. 5. The engine torque $M$ vs engine speed $n$ for $25 \%, 50 \%, 75 \%$ and $100 \%$ loading of the KIA 2.7 (J2) diesel engine

of tetrahedral finite elements was created automatically by the commercial software and shown in Figure $7 \mathrm{~b}$. The boundary conditions were following (Figure 7c):

- the outer cylindrical surface of the evolventic joint was fixed in its radial and its axial direction,

- the outer cylindrical surfaces, being the base surface for the dual wheel hub, were fixed in their tangential (peripheral) direction,

- the outer cylindrical surface of the evolventic joint was loaded by the torsional torque $M_{z}$ equal to $337 \mathrm{Nm}$,

- the flange of the rear-axle shaft was loaded by the bending torque $M_{x}$ with value equal to 0 and to that when the von Misses stresses of material of the rear-axle shaft reach the allowable value of fatigue strength $k_{\text {fatigue }}$.

\section{Model of loading the bearing set of the rear dual wheel}

Bearing of the most loaded outer rear dual wheel of the truck during cornering was considered. It was assumed that the bearing set was loaded by the vertical reaction $\mathrm{R}_{\mathrm{ro}}$ and half of the force $\mathrm{P}_{\mathrm{n}}$ driving the truck. In order to simplify the analysis, it was also assumed that the considered bearing was loaded only by such forces. The scheme of loading of the bearing set of the truck rear dual wheel was shown in Figure 8.

The total radial force loading the bearing set was estimated from the equation below.

$$
F_{\text {rtotal }}=\sqrt{R_{\text {ro }}^{2}+\left(0.5 \cdot P_{n}\right)^{2}}
$$

It was assumed that the tapered bearings were of the same type and were equally loaded. 


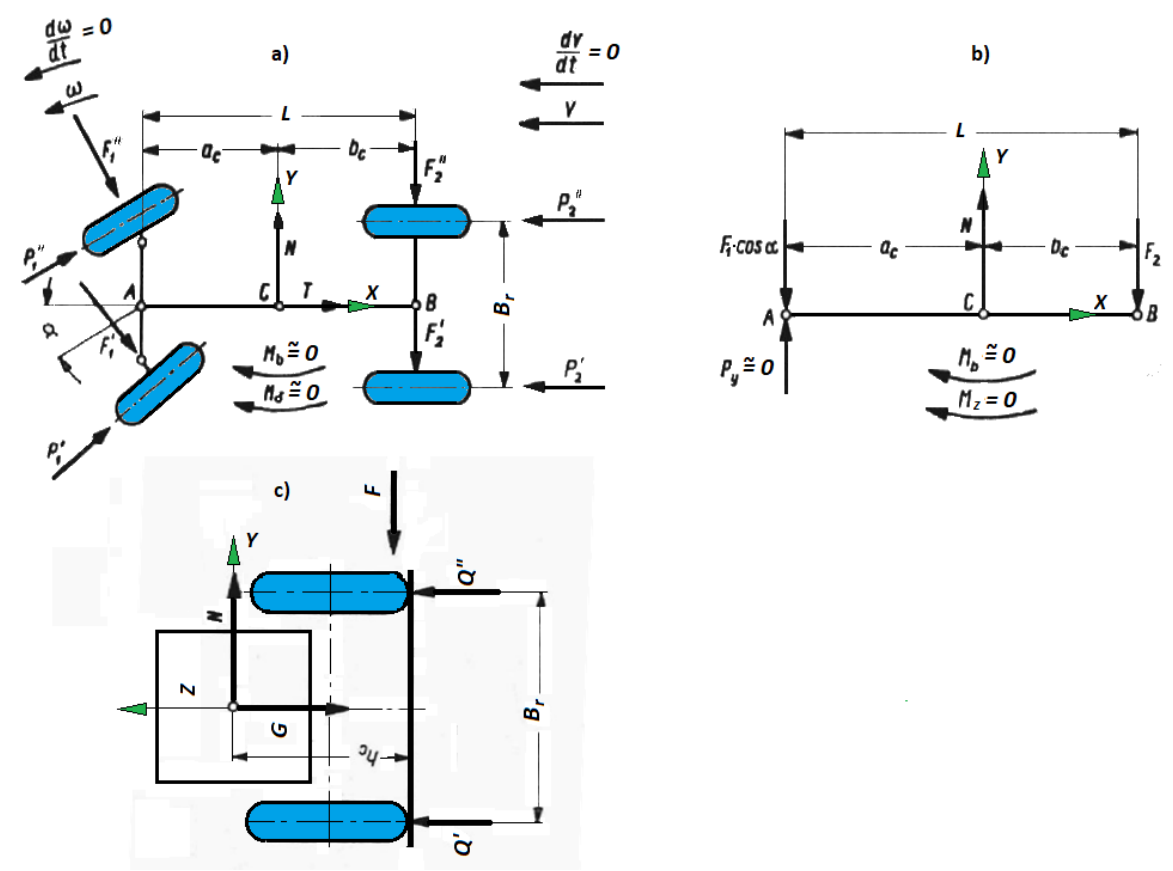

Fig. 6. a) The scheme of forces and torques acting on the vehicle during cornering, b) simplified sets of the forces and the torques in plane XY, c) simplified sets of the forces in plane YZ.

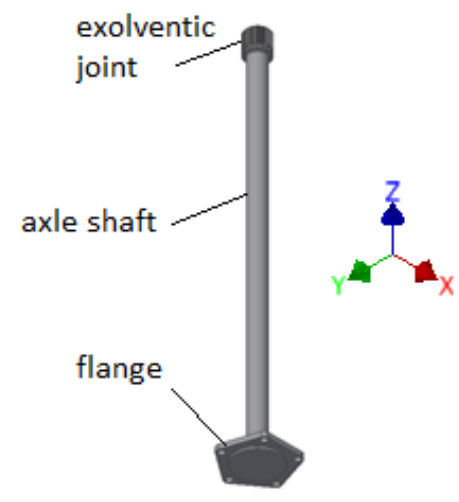

a)

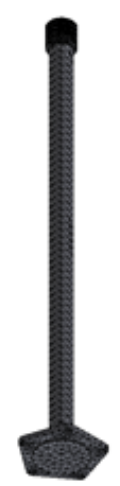

b)

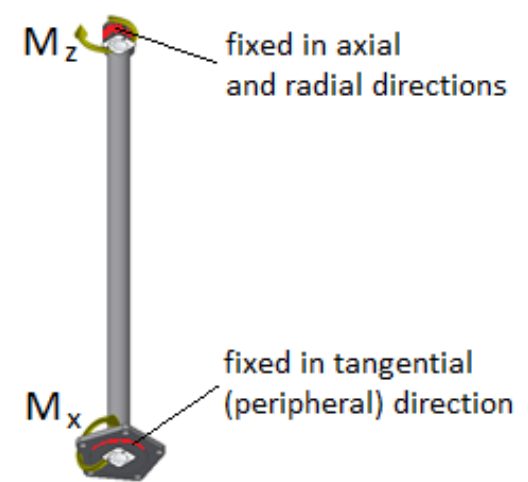

c)

Fig. 7. The model of the rear-axle shaft of the KIA K2700 truck. A) geometry of rear-axle shaft, b) grid of the finite elements, c) boundary conditions.

The equivalent dynamic bearing load of a single tapered roller bearing was calculated from conditions.

$$
\begin{aligned}
& F_{\text {atotal }}=\frac{0.5 \cdot F_{\text {rtotal }}}{Y} \\
& \frac{F_{\text {atotal }}}{F_{\text {rtotal }}} \leq e \rightarrow P_{e q}=F_{\text {rtotal }} \\
& \frac{F_{\text {atotal }}}{F_{\text {rtotal }}}>e \rightarrow P_{e q}=0.4 \cdot F_{\text {rtotal }}+Y \cdot F_{\text {atotal }}
\end{aligned}
$$

For the analyzed tapered roller bearing, the parameters $\mathrm{Y}=1.5$ and $\mathrm{e}=0.4$ and the fatigue limit $F_{\text {fatigue }}=8800 \mathrm{~N}$.

\section{RESULTS}

Figure 9 presented the parts of the broken rear-axle shaft of a KIA K2700 truck. The crosssection of the left part (Fig. 9a) revealed the traces characteristic of the presence of fatigue crack in the form of a focus of that crack, probably initiated by the post-hardened heterogeneity of the structure at the border of the core and surface layer, or by the presence of non-metallic inclusions. In addition, the traces in the mentioned cross-section indicated the occurrence of separation of materials as a result of tearing. However, it 


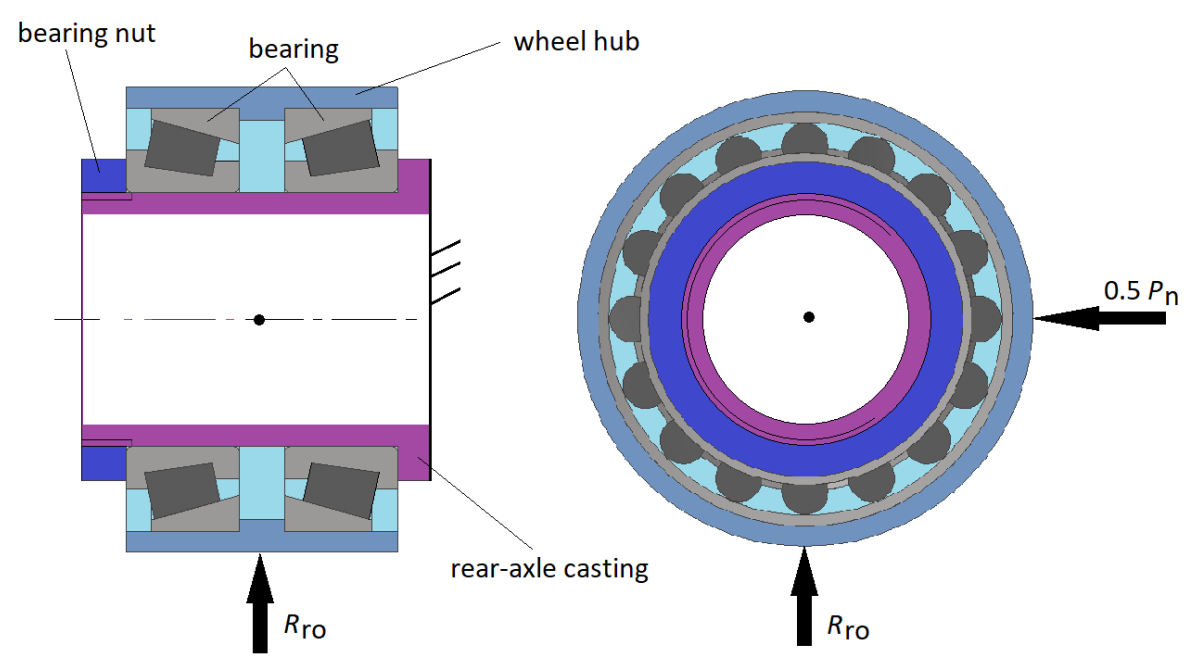

Fig. 8. The scheme of loading of the bearing set of the truck rear dual wheel

resulted from a complex state of stresses (torsion and tensile) rather than from the torsion or bending moment itself. On the outer surface of the rear-axle shaft, there were also traces of rubbing the outer surface against the inner surface of the rear-axle casting. The part on the right (Fig. 9b) revealed the traces of rubbing between a fragment of the outer surface of the rear axle-shaft against the inner surface of the rear-axle casting. The aforementioned fragment was located near the place of rupture and breakage of the rear-axle shaft. In addition, the traces of the occurrence of separation of materials as a result of tearing were clearly visible.

The obtained values of the von Misses stresses in the material of the rear-axle shaft where the bending torque $M_{x}$ was equal to $0 \mathrm{MPa}$ was showed in Figure 10. It was visible that the von Misses stresses were below the value of $k_{\text {fatigue }}$.
Figure 11 presented the values of the von Misses stresses obtained where the torque Mx was equal to $140 \mathrm{MPa}$. It was visible that the von Misses stresses reached the value of $k_{\text {fatigue }}$.

Figure 12 presented the values of total displacement obtained where the torque $M_{x}$ was equal to $140 \mathrm{MPa}$. It was visible that near the middle of rear-axle shaft, displacement could reach values of $0.5 \mathrm{~mm}$.

Figure 13 presented the values of displacement parallel to the axis of rear-axle shaft obtained where the bending torque $M_{x}$ was equal to $140 \mathrm{MPa}$. It was visible that near the middle of rear-axle shaft displacement could reach values of $0.09 \mathrm{~mm}$.

The calculated equivalent dynamic load $P_{e q}$ of the analyzed single tapered roller bearing for the truck during cornering reached value 11963
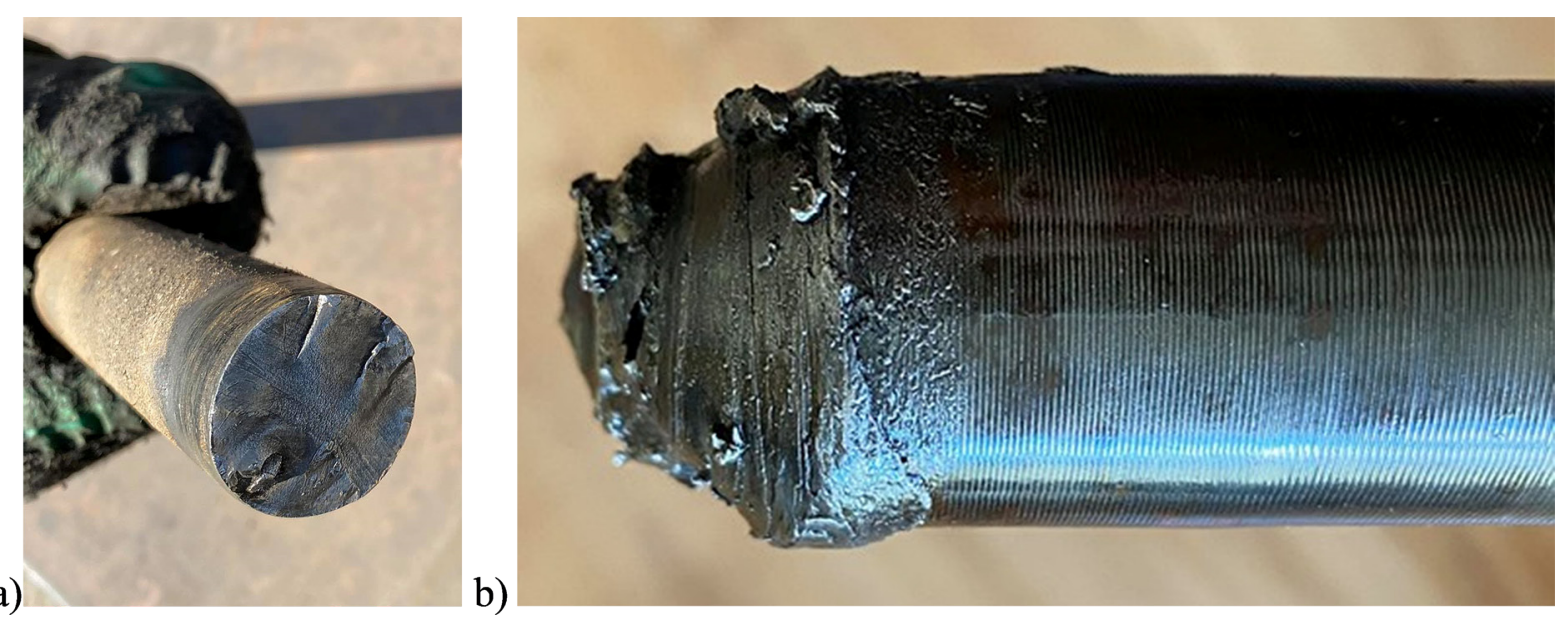

Fig. 9. Two parts of the broken rear half-shaft of a KIA K2700 truck. a) part from the side of the rear-axle housing, b) part from the side of the truck dual wheel. 

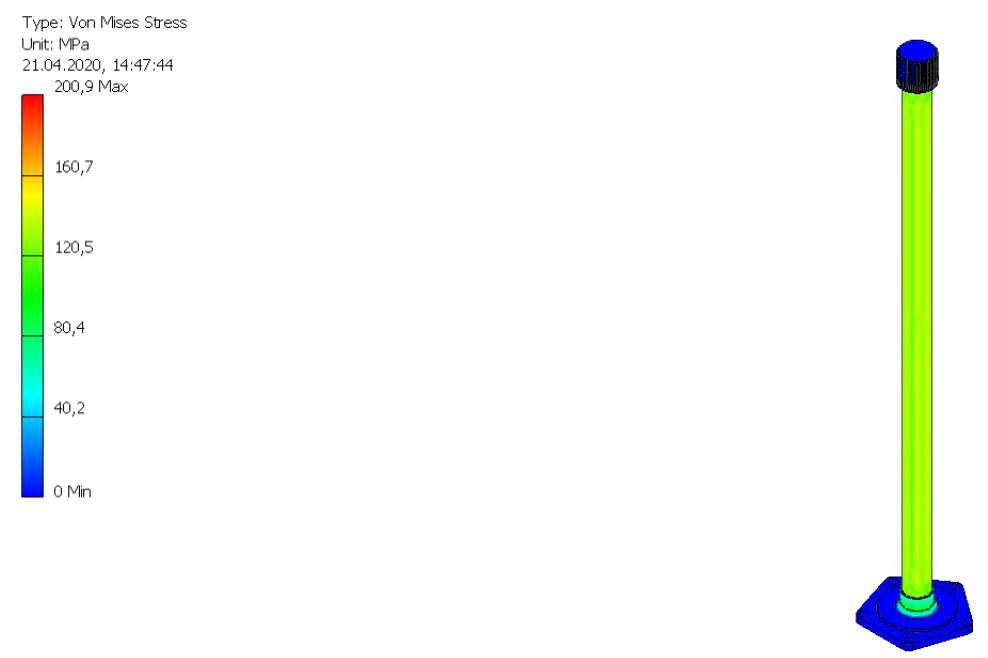

Fig. 10. The von Misses stresses in material of the rear-axle shaft where the bending torque $M_{x}$ was equal to $0 \mathrm{MPa}$.
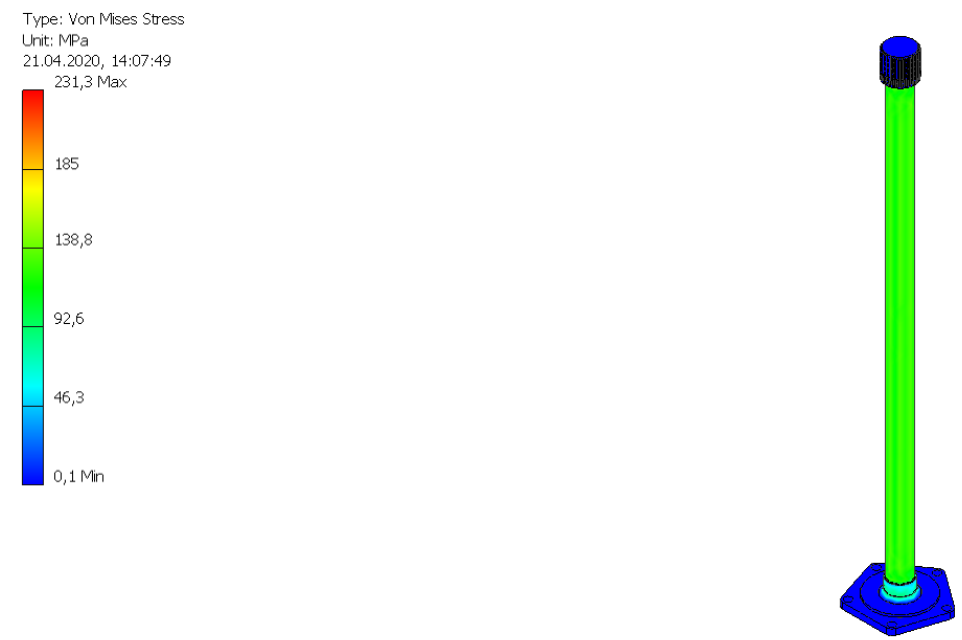

Fig. 11. The von Misses stresses obtained where the bending torque $M_{x}$ was equal to $140 \mathrm{MPa}$. It was visible that the von Misses stresses reached the value of $k_{\text {fatigue }}$.

which was greater than the fatigue limit $F_{\text {fatigue }}$ by $36 \%$. This means that the fatigue of the bearings may have occurred during the truck drive.

\section{CONCLUSIONS}

On the basis of the results obtained from observations and the numerical analysis, the probable cause of the axle breakage was established. It was as follows: the simultaneous overloading of the truck and cornering caused a significant overload of the tapered bearing system of the rear outer dual wheel. Local raceway fatigue and loosening of the bearing nut resulted in an increased clearance in the tapered roller bearing system and, as a result, cyclical local loss of contact between the bearing rollers and their raceways, and possibly also large deformations of the inner raceways of the bearings and the rear-axle casting on which they were mounted. This in turn enabled cyclical axial displacement of the wheel hub as a result of its oscillating movement relative to the center of the dual wheel - this would correspond to the parametric vibrations associated with the cyclical change in the rigidity of the wheel mounting system. During such fluctuations, there was a cyclical bending of the axle flange connected with screws to the hub. If the play in the bearing system and deformations of the bearing raceway and the rear-axle casting were large, then the values of the cyclically variable bending moment 

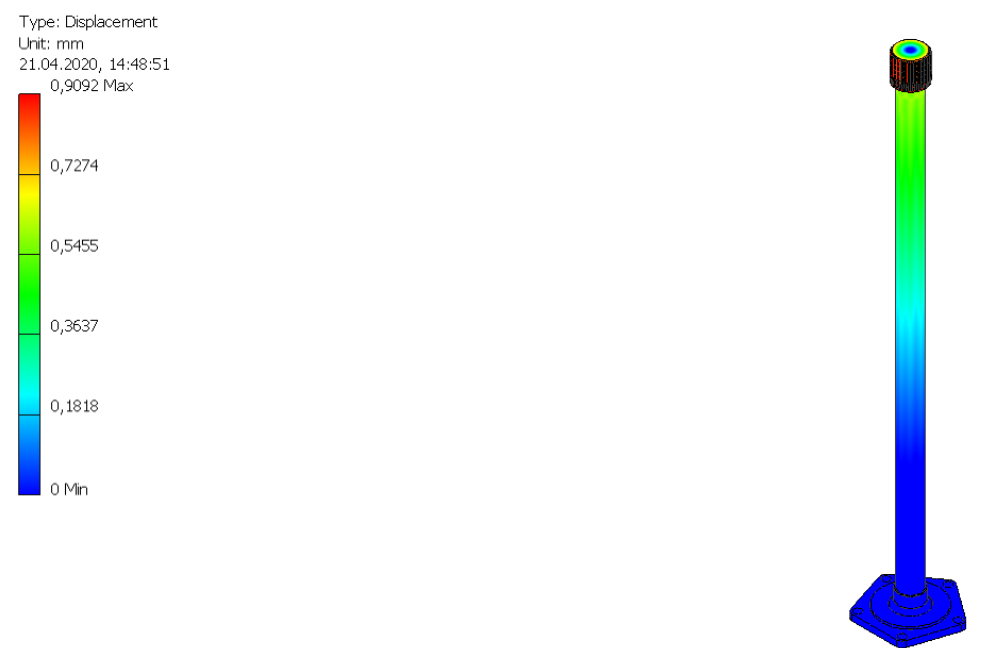

Fig. 12. The values of total displacement obtained where the torque $M_{x}$ was equal to $140 \mathrm{MPa}$.
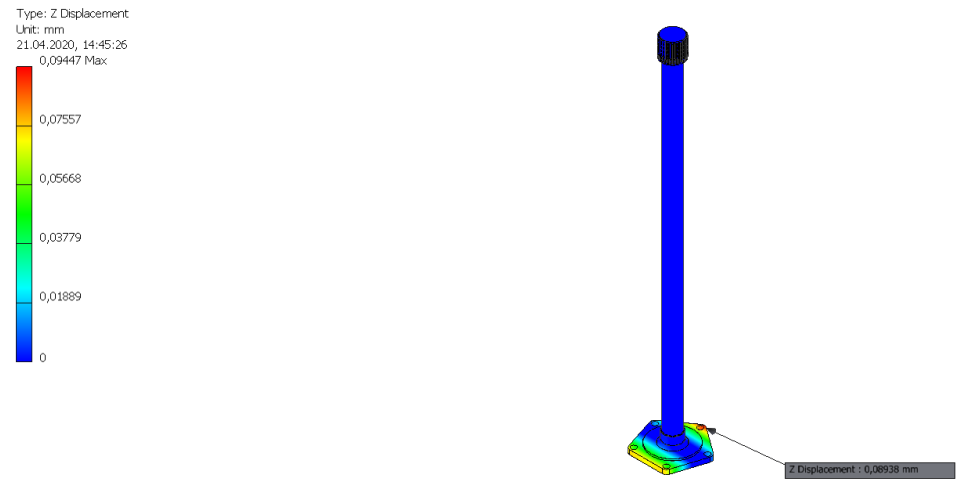

Fig. 13. The values of displacement parallel to the axis of rear-axle shaft ( $Z$ axis) obtained where the bending torque $M_{x}$ was equal to $140 \mathrm{MPa}$.

could also reach large values. With the simultaneous impact of the torque, they caused a complex state of stress the values of which exceeded the fatigue strength of the drive shaft material. In addition, as a result of the simultaneous occurrence of a large overload of the vehicle and cornering, a large cyclic bending of the rear-axle casting could occur. The latter, together with the cyclically operating shafts, could enable rubbing of the outer surface of the shaft against the inner surface of the rear-axle casting. However, if the clearance in the bearings and the rear-axle casting deformations were not too large, then the split of the axle shaft had to be initiated by the presence of some local heterogeneity in the axle shaft material, for example, non-metallic inclusions or grains with a brittle and hard structure formed during the hardening process at the interface between the surface layer and the axle shaft. If there was no abrasion of the outer surface of the shaft with the inner surface of the rear-axle casting, then the visible traces of abrasion had to occur already during the detachment of the shaft core material - that is, during the development of its macro-cracking.

\section{REFERENCES}

1. Das S., Mukhopadhyay G. and Bhattacharyya S. Failure analysis of axle shaft of a fork lift. Case Studies in Engineering Failure Analysis, 3, 2015, 46-51, https://doi.org/10.1016/j.csefa.2015.01.003.

2. Dilich MA and Goebelecker JM. Truck Rollover. Motor Carrier Safety Administration (MC-R/MCRRA) 1997, 20.

3. FMCSA Report to Congress on the large truck crash causation study. Federal Motor Carrier Safety Administration (MC-R/MC-RRA), 2006.

4. Garcia L.O., Wilson F.R. and Innes J.D. Heavy truck dynamic rollover: effect of load distribution, 
cargo type, and road design characteristics. Transportation Research Record No. 1851, 2003.

5. Green SD. Prevent heavy truck rollovers. Traffic Safety, National Safety Council, 2(4), 2002, 1213, 22.

6. Guimaraes A.V., Brasileiro P.C., Giovanni G.C., Costa L.R.O. and Araujo L.S. Failure analysis of a half-shaft of a formula SAE racing car. Case Studies in Engineering Failure Analysis, 7, 2016, 17-23, https://doi.org/10.1016/j.csefa.2016.05.002.

7. Hillier V.A.W., Coombes P. Hillier's Fundamentals of Motor Vehicle Technology, 5th edition, Cheltenham, UK: Nelson Thornes, 2004.

8. kia_broschure_k2700.pdf. www.kia.co.za (accessed on May 26, 2020).

9. KIA K2500-K2700-K3000s-K4000g. https:// www.kia.com/worldwide/vehicles/k2500-k2700k3000s-k4000g.do (accessed on May 26, 2020).

10. KIA Model K2700, K2500. http:/www.kiamo- torsnigeria.com/model $/ \mathrm{k} 2700 \mathrm{k} 2500 /$ (accessed on May 26, 2020).

11. KIA K2700 II T 75879-75937 Specification. https://kiamotor.en.ec21.com/Specification_KIA_ K2700_II_T--75879_75937.html.

12. Khattak AJ, Schneider RJ. How can we prevent rollovers and reduce injury severity in single-vehicle large truck crashes? Proc of International Truck and Bus Safety Research and Policy Symposium, Knoxville: University of Tennessee, USA 2002, 189-199.

13. McKnight AJ and Bahouth GT. Analysis of large truck rollover crashes. Ann Adv Automot Med., 52, 2008, 281-288.

14. Tire Tech: Dual Tires for Light Truck Use, https:// www.tirerack.com/tires/tiretech/tiretech.jsp (accessed on May 26, 2020).

15. Truck. Why are trucks so important? https://www. acea.be/automobile-industry/trucks (accessed on May 26, 2020). 